\title{
Toxicity evaluation of ethanol treatment during in vitro maturation of porcine oocytes and subsequent embryonic development following parthenogenetic activation and in vitro fertilization
}

\author{
SANGHOON LEE*, EUNHYE KIM* and SANG-HWAN HYUN \\ Laboratory of Veterinary Embryology and Biotechnology (VETEMBIO), College of Veterinary Medicine, \\ Chungbuk National University, Cheongju, Chungbuk 361-763, Republic of Korea
}

Received May 13, 2014; Accepted September 2, 2014

DOI: $10.3892 / \mathrm{ijmm} .2014 .1924$

\begin{abstract}
Ethanol is frequently used as a solvent in several techniques for in vitro production (IVP). It is also used for the parthenogenetic activation (PA) of oocytes. Although a number of studies have suggested that ethanol has detrimental effects on fibroblasts and neuronal cells, little attention has been paid to the effects of ethanol on porcine oocytes. Thus, the aim of this study was to evaluate the effects of the addition of ethanol to in vitro maturation (IVM) medium. We investigated the effects of ethanol $(0,1$ and $3 \%)$ on the following parameters: nuclear maturation, intracellular glutathione (GSH) and reactive oxygen species (ROS) levels, and subsequent embryonic development following PA and in vitro fertilization (IVF). After $44 \mathrm{~h}$ of IVM, the $3 \%$ group showed a significant $(\mathrm{P}<0.05)$ decrease in nuclear maturation $(34.0 \%)$ compared with the control group (70.3\%). The 1 and 3\% groups exhibited a significant $(\mathrm{P}<0.05)$ decrease in GSH levels and an increase in ROS levels compared with the control group. Compared with the control group, the $3 \%$ group had significantly $(\mathrm{P}<0.05)$ lower cleavage rates following PA (51.6 vs. 86.9\%) and IVF (53.2 vs. 70.6\%), as well as lower blastocyst formation rates and decreased total cell numbers following PA (11.3\% and 31.8 vs. $53.6 \%$ and 65.4 , respectively) and IVF (4.1\% and 22.0 vs. $36.1 \%$ and 70.3 , respectively). We evaluated the mRNA expression levels of DNA repair-related and apoptosis-related
\end{abstract}

Correspondence to: Professor Sang-Hwan Hyun, Laboratory of Veterinary Embryology and Biotechnology (VETEMBIO), College of Veterinary Medicine, Chungbuk National University, 52 Naesudong-ro, Heungduk-gu, Cheongju, Chungbuk 361-763, Republic of Korea

E-mail: shhyun@cbu.ac.kr

*Contributed equally

Key words: ethanol, toxicity, porcine oocyte, in vitro maturation, embryonic development genes in the cumulus oocyte complexes (COCs). The $1 \%$ ethanol group showed significantly $(\mathrm{P}<0.05)$ higher mRNA expression levels of poly(ADP-ribose) polymerase-1 (PARP-1), Bax, Bak and caspase-3, and the 3\% ethanol group had significantly $(\mathrm{P}<0.05)$ increased PARP- 1 , Bax and caspase- 3 mRNA expression levels compared with the control group. Our results suggest that treatment with $>1 \%$ ethanol during IVM exerts a toxic effect on the developmental potential of PA and IVF porcine embryos by decreasing the intracellular GSH level, thereby increasing the intracellular ROS level and upregulating the expression of apoptosis-related genes.

\section{Introduction}

The in vitro production (IVP) of embryos has been widely used in reproduction technology. Pigs have been used in biomedical research for decades as disease models, disease-resistance animals and genetically-defined models for surgery and xenotransplantation as their anatomy and physiology are similar to those of humans $(1,2)$. However, the potential of porcine embryos to develop in vitro is still inferior to that of embryos obtained in vivo. One of the reasons of this inferiority is thought to be improper in vitro maturation (IVM) systems. Several researchers have made tremendous efforts to improve IVM conditions by the addition of pharmacological compounds $(3,4)$. The addition of pharmacological compounds in IVM medium requires the use of solvents in order to dissolve these compounds.

Ethanol, which is known as a cryoprotectant $(5,6)$ and an inducer of the artificial parthenogenetic activation (PA) of oocytes (7-10), is frequently used in a number of techniques for IVP as one of the solvents for pharmacological compounds that are not dissolved in water. For example, in a previous study on the effect of lanosterol supplementation to porcine IVM medium, an ethanol concentration of $1.68 \%$ was used for the lanosterol solvent (3). Moreover, ethanol has been used for the addition of meiosis-activating sterols (MAS) to IVM medium to improve the conditions of IVM (4). However, although a number of studies have suggested that high concentrations of ethanol have detrimental effects on several cell types (11-13), 
little attention has been paid to the effects of low concentrations ethanol, which are often used as a solvent in the IVM of porcine oocytes.

Previous studies have demonstrated that ethanol promotes apoptotic cell death in cultured neurons (14). There are multiple apoptotic pathways activated in cells by ethanol, including the caspase-dependent pathway and caspase-independent apoptotic pathway known as the poly(ADP-ribose) polymerase-1 (PARP-1)-related pathway. Caspases have been thought to be the central executioners of the apoptotic pathway (15). Apoptosis can be directed by the activation of caspases, which cleave specific substrates and trigger cell death. PARP-1 is a zinc ( $\mathrm{Zn}$ ) finger nuclear protein activated by DNA strand-breaks and utilizes $\beta$-nicotinamide adenine dinucleotide $(\beta-N A D)$ as a substrate to catalyze the synthesis of ADP-ribose polymers on nuclear proteins, including PARP-1 itself (16). Thus, PARP-1 plays a key role in caspase-independent cell death and survival under multiple stress conditions $(17,18)$.

Considering how ethanol influences cells, the potential effects of ethanol on IVM may be related to apoptosis. Therefore, the aim of this study was to evaluate the toxic effects of the addition of low concentrations of ethanol to IVM medium for the culture of immature porcine oocytes. For this purpose, various parameters were compared in mature porcine oocytes, including nuclear maturation, intracellular levels of glutathione (GSH), intracellular levels of reactive oxygen species (ROS), mRNA expression levels of DNA repair- and apoptosis-related genes [proliferating cell nuclear (PCNA), PARP-1, Bax, Bak and caspase-3] in the cumulus oocyte complexes (COCs) at the end of the maturation period and embryo developmental competence following PA and in vitro fertilization (IVF).

\section{Materials and methods}

Chemicals. All chemicals and reagents used in this study were purchased from Sigma-Aldrich Chemical Co. (St. Louis, MO, USA), unless otherwise stated.

Oocyte collection and IVM. Ovaries of prepubertal gilts were collected at a local abattoir and transported to the laboratory within $2 \mathrm{~h}$ in physiological saline supplemented with $100 \mathrm{IU} / \mathrm{l}$ penicillin $\mathrm{G}$ and $100 \mathrm{mg} / \mathrm{ml}$ streptomycin sulfate at $32-35^{\circ} \mathrm{C}$. The COCs in the ovaries were aspirated from 3- to 6- $\mathrm{mm}$ diameter superficial follicles using an 18-gauge needle attached to a $10 \mathrm{ml}$ disposable syringe and allowed to settle down as sediment in $15 \mathrm{ml}$ conical tubes at $37^{\circ} \mathrm{C}$ for $5 \mathrm{~min}$. The supernatant was discarded and the precipitate was resuspended with HEPES-buffered Tyrode's medium (TLH) containing $0.05 \%$ (wt/vol) polyvinyl alcohol (PVA) (TLH-PVA). Subsequently, it was observed under a stereomicroscope for recovering the COCs. Only COCs having $\geq 3$ uniform layers of compact cumulus cells and a homogeneous cytoplasm were selected and washed 3 times in TLH-PVA. Approximately 60 COCs were placed into each well of a 4-well Nunc dish (Nunc, Roskilde, Denmark) containing $500 \mu \mathrm{l}$ of culture medium (TCM199; Invitrogen Corp., Carlsbad, CA, USA) which was supplemented with $0.6 \mathrm{mM}$ cysteine, $0.91 \mathrm{mM}$ sodium pyruvate, $10 \mathrm{ng} / \mathrm{ml}$ epidermal growth factor, $75 \mu \mathrm{g} / \mathrm{ml}$ kanamycin, $1 \mu \mathrm{g} / \mathrm{ml}$ insulin, $10 \%$ (vol/vol) porcine follicular fluid (pFF), $10 \mathrm{IU} / \mathrm{ml}$ equine chronic gonadotropin (eCG) and $10 \mathrm{IU} / \mathrm{ml}$ hCG (Intervet, Inc., Boxmeer, the Netherlands). The selected COCs were incubated at $39^{\circ} \mathrm{C}$ with $5 \% \mathrm{CO}_{2}$ in $95 \%$ humidified air for IVM. Following 21-22 h of maturation with hormones, the COCs were washed twice in fresh hormone-free IVM medium and then cultured in hormone-free IVM medium for an additional 21-22 h. The COCs during IVM were treated with or without low concentrations $(0,1$ and $3 \%)$ of ethanol according to the experimental design.

Evaluation of nuclear maturation. The oocytes at the metaphase II (MII) stage, 42-44 h after IVM, were sampled to analyze nuclear maturation. Samples of oocytes (a total of 509 oocytes was used for the analysis of nuclear maturation) were by gently pipetting with $0.1 \%$ hyaluronidase in IVM medium and washed in TLH-PVA. The denuded oocytes were fixed with fixative solution containing $2 \%$ formaldehyde and $0.25 \%$ glutaraldehyde, and stained with TLH-PVA containing $5 \mu \mathrm{g} / \mathrm{ml}$ Hoechst 33342 for at least $5 \mathrm{~min}$. The stained oocytes were evaluated using a fluorescence microscope (Nikon Corp., Tokyo, Japan) and classified as germinal vesicle (GV), metaphase I (MI), anaphase-telophase I (AT-I), or MII according to the meiotic maturation stage. The oocytes at MII were considered to have matured.

Measurement of intracellular GSH and ROS levels. The oocytes at 42-44 $\mathrm{h}$ after IVM were sampled to determine intracellular GSH and ROS levels. The measurement of GSH and ROS levels was carried out according to previously described methods (19,20). In brief, 2',7'-dichlorodihydrofluorescein diacetate $\left(\mathrm{H}_{2} \mathrm{DCFDA}\right.$; Invitrogen Corp.oration, Paris, France) and 4-chloromethyl-6.8-difluoro-7-hydroxycoumarin (CellTracker Blue; CMF2HC; Invitrogen Corp.) were used to detect intracellular ROS levels as green fluorescence and GSH levels as blue fluorescence, respectively. From each treatment group, 10 oocytes were incubated (in the dark) for $30 \mathrm{~min}$ in TLH-PVA supplemented with $10 \mu \mathrm{M} \mathrm{H}_{2}$ DCFDA and $10 \mu \mathrm{M}$ CellTracker Blue. Following incubation, the oocytes were washed with Dulbecco's phosphate buffered saline (DP BS) (Invitrogen Corp.) containing 0.1\% (wt/vol) PVA, placed into $10-\mu 1$ droplets, and fluorescence was evaluated under an epifluorescence microscope (TE300; Nikon Corp.) with UV filters (460 nm for ROS and $370 \mathrm{~nm}$ for GSH). These fluorescence images were saved as graphic files in TIFF format. The experiment was replicated 3 times with a total of examined oocytes (GSH samples, $n=28$; ROS samples, $n=28$ ).

Each intracellular GSH level was quantified according to the method previously described by Baker et al (21) with some modifications. Briefly, MII oocytes from each experimental group were washed 3 times in $0.2 \mathrm{M}$ sodium phosphate buffer $\left(\mathrm{Na}_{2} \mathrm{HPO}_{4}, \mathrm{NaH}_{2} \mathrm{PO}_{4}\right.$, and $10 \mathrm{mM}$ EDTA-2Na, $\mathrm{pH}$ 7.2) and groups of 50-60 oocytes (per sample) in $10 \mu \mathrm{l}$ sodium phosphate buffer were transferred to $1.7 \mathrm{ml}$ microfuge tubes; $10 \mu 1$ of $1.25 \mathrm{mM}$ phosphoric acid (final concentration of $0.625 \mathrm{M} \mathrm{H}_{3} \mathrm{PO}_{4}$ ) in distilled water was added to each sample. Tubes containing the samples were frozen at $-80^{\circ} \mathrm{C}$ until analysis. GSH concentrations in the oocytes were measured using a 5,5'-dithiobis-(2-nitrobenzoic acid) (DTNB)-GSH reductase (GSSG) recycling assay. The frozen samples were thawed at room-temperature, vortexed, centrifuged and microscopically 
evaluated to ensure complete lysis of the oocytes prior to the assay. The supernatants were transferred to a 96-well microtiter plate, and for each sample, $700 \mu 1$ of $0.33 \mathrm{mg} / \mathrm{ml}$ nicotinamide adenine dinucleotide phosphate (NADPH) in $0.2 \mathrm{M}$ assay buffer containing $10 \mathrm{mM}$ EDTA (stock buffer, $\mathrm{pH}$ 7.2), $100 \mu \mathrm{l}$ of $6 \mathrm{mM}$ DTNB in the stock buffer and $180 \mu \mathrm{l}$ of distille water and $1 \mathrm{U}$ per sample of DTNB-GSH reductase $(441 \mathrm{U} / \mathrm{ml})$ were added to a conical tube, mixed and immediately added to the sample. The plate was immediately placed in a microtiter plate reader, and optical density was measured with a $405 \mathrm{~nm}$ filter (EMax; Molecular Devices, Sunnyvale, CA, USA). The formation of 5-thio-2 nitrobenzoic acid was monitored every $30 \mathrm{sec}$ for $3 \mathrm{~min}$. Standard curves were prepared for each assay and the GSH content per sample was determined by a standard curve. The GSH concentrations (pmol/oocyte) were calculated by dividing the total concentration per sample by the total number of oocytes present in the sample. The experiment was replicated 3 times.

PA of oocytes. For PA, the COCs were denuded at $42-44 \mathrm{~h}$ following IVM by gently pipetting with $0.1 \%$ hyaluronidase, washed 3 times in TLH-PVA and then rinsed twice in activation medium $(280 \mathrm{mM}$ mannitol solution containing $0.01 \mathrm{mM} \mathrm{CaCl}_{2}$ and $0.05 \mathrm{mM} \mathrm{MgCl}_{2}$ ). For activation, the matured oocytes at the MII stage were placed between electrodes covered with activation medium in a chamber connected to an electrical pulsing machine (LF101; Nepa Gene, Co., Ltd., Ichikawa, Japan). Oocytes were activated with 2 direct-current (DC) pulses of $120 \mathrm{~V} / \mathrm{mm}$ for $60 \mu \mathrm{sec}$. Following electrical activation, the oocytes were immediately placed into IVC medium supplemented with $5 \mu \mathrm{g} / \mathrm{ml}$ of cytochalasin B for $6 \mathrm{~h}$. The PA embryos were washed 3 times in fresh IVC medium, placed into $30 \mu \mathrm{IVC}$ droplets (10 gametes per drop) covered with pre-warmed mineral oil, and then cultured at $39^{\circ} \mathrm{C}$ in a humidified atmosphere of $5 \% \mathrm{O}_{2}, 5 \% \mathrm{CO}_{2}$, and $90 \% \mathrm{~N}_{2}$ for 7 days.

IVF and culture. For IVF, the COCs were denuded at $42-44 \mathrm{~h}$ following IVM by gently pipetting with $0.1 \%$ hyaluronidase and washed 3 times in TLH-PVA. Groups of 15 matured oocytes at the MII stage were randomly placed into $40 \mu 1$ droplets of modified Tris-buffered medium (mTBM) in a 35x10 mm Petri dish (Falcon; Becton Dickinson Labware, Franklin Lakes, NJ, USA) covered with pre-warmed mineral oil. Subsequently, liquid semen supplied weekly from the Veterinary Service Laboratory (Department of Livestock Research, Yong-in, Korea) was kept at $17^{\circ} \mathrm{C}$ for 5 days prior to use. The semen sample was washed twice with DPBS supplemented with $0.1 \%$ BSA by centrifuging at 2,000 $\mathrm{x}$ g for $2 \mathrm{~min}$. After washing, the sperm pellet was resuspended in mTBM, as previously described (22), which had been pre-equilibrated for $18 \mathrm{~h}$ at $39^{\circ} \mathrm{C}$ at $5 \% \mathrm{CO}_{2}$. After appropriate dilution, $5 \mu \mathrm{l}$ of the sperm suspension were added to a $40 \mu \mathrm{l}$ drop of fertilization medium (mTBM) to set a final sperm concentration of $1 \times 10^{6} \mathrm{sperm} / \mathrm{ml}$. Immediately before fertilization, sperm motility was assessed and $>80 \%$ motile sperm was used in each experiment. To use stored liquid semen, a modified two-step culture system (23) was used. The oocytes were co-incubated with sperm for $20 \mathrm{~min}$ at $39^{\circ} \mathrm{C}$ in a humidified atmosphere of $5 \% \mathrm{CO}_{2}$ and $95 \%$ air. After $20 \mathrm{~min}$ of co-incubation with sperm, the loosely attached sperm was removed from the zona pellucida (ZP) by gentle pipetting. Subsequently, the oocytes were washed 3 times in mTBM and incubated in mTBM without sperm for $5-6 \mathrm{~h}$ at $39^{\circ} \mathrm{C}$ in a humidified atmosphere of $5 \% \mathrm{CO}_{2}$ and $95 \%$ air. Thereafter, the gametes were washed 3 times in embryo culture medium and cultured in $25 \mu 1$ microdrops (10 gametes/drop) of porcine zygote medium 3 (PZM3), as previously described (24) with pre-warmed mineral oil. The embryos with cultured drops were incubated at $39^{\circ} \mathrm{C}$ for $168 \mathrm{~h}$ under a humidified atmosphere of $5 \% \mathrm{O}_{2}, 5 \% \mathrm{CO}_{2}$ and $90 \% \mathrm{~N}_{2}$. In all the experiments, the culture medium was renewed at $48 \mathrm{~h}$ (day 2) and $96 \mathrm{~h}$ (day 4) following IVF.

Embryo evaluation and total cell count of blastocysts. The day on which PA or IVF was performed was considered day 0 . The embryos were evaluated under a stereomicroscope for cleavage on day 2 (48 h). Evenly cleaved embryos were classified into 3 groups (2-3, 4-5 and 6-8 cells). Blastocyst formation was assessed on day 7 (168 h) following IVF, and blastocysts were classified according to the degree of expansion and hatching status, as previously described (25): early blastocyst (small blastocyst with a blastocoel equal to or less than half of the embryo volume), expanded blastocyst (a large blastocyst with a blastocoel greater than half of the embryo volume or blastocyst with a blastocoel completely filling the embryo) and hatched blastocyst (hatching or already hatched blastocyst). To count the total cell number of blastocysts, on day 7, the blastocysts were collected and washed in $1 \%$ (wt/vol) PBS-BSA and stained with $5 \mu \mathrm{g} / \mathrm{ml}$ Hoechst 33342 (bisbenzimide) for 5 min. After a final wash in PBS-BSA, the embryos were briefly fixed in 4\% paraformaldehyde in PBS. Subsequently, the blastocysts were mounted on glass slides in a drop of $100 \%$ glycerol, squashed gently with a cover slip and observed under a fluorescence microscope (Nickon Corp., Tokyo, Japan) at $\mathrm{x} 400$ magnification.

Gene expression analysis by quantitative reverse transcription polymerase chain reaction ( $R T-q P C R)$. For the gene expression analysis, groups (control, 1 and 3\% ethanol) of 140-150 mature COCs were separately sampled under a stereomicroscope. All samples were stored at $80^{\circ} \mathrm{C}$ until analysis. The mRNA expression of PCNA, PARP-1, Bak, Bax and caspase-3 in the COCs was analyzed by RT-PCR. Total RNA was extracted using TRIzol reagent (Invitrogen Corp.), according to the manufacturer's instructions, and the total RNA concentration was determined by measuring the absorbance at $260 \mathrm{~nm}$. First-strand complementary DNA (cDNA) was prepared by subjecting $1 \mu \mathrm{g}$ of total RNA to reverse transcription using Moloney murine leukemia virus (MMLV) reverse transcriptase (Invitrogen Corp.) and random primers (9-mers; Takara Bio, Inc., Otsu, Shiga, Japan). To determine the conditions for the logarithmic phase PCR amplification of target mRNA, 1- $\mu \mathrm{g}$ aliquots were amplified using differing numbers of cycles. The housekeeping gene, GAPDH, was PCR-amplified to rule out the possibility of RNA degradation and to control for the variation in mRNA concentrations in the reverse transcription (RT) reaction. A linear relationship between the PCR product band visibility and the number of amplification cycles was observed for the target mRNAs. The GAPDH and target genes were quantified using 40 cycles. The 
Table I. Primer sequences used for gene expression analysis.

\begin{tabular}{llcc}
\hline mRNA & \multicolumn{1}{c}{ Primer sequences } & $\begin{array}{c}\text { Product } \\
\text { size (bp) }\end{array}$ & $\begin{array}{c}\text { GenBank } \\
\text { accession no. }\end{array}$ \\
\hline GAPDH & F: 5'-GTCGGTTGTGGATCTGACCT-3' & 207 & NM_001206359.1 \\
PCNA & R: 5'-TTGACGAAGTGGTCGTTGAG-3' & & XM_003359883 \\
PARP-1 & F: 5'-CCTGTGCAAAAGATGGAGTG-3' & 187 & \\
Rax & F'-GGAGAGAGTGGAGTGGCTTTT-3' & & XM_003357641.1 \\
Bak & R: 5'-GATTGGAGGACGTCCCTGTGG-3' & 202 & XM_003127290 \\
Caspase-3 & F: 5'-TGCCTCAGGATGCATCTACC-3' & 199 & \\
& R: 5'-AAGTAGAAAAGCGCGACCAC-3' & & XM_001928147 \\
& F: 5'-GCGGAAAACGCCTATGAGTA-3' & 189 & \\
& R: 3'-GCAGTGATGCAGCATGAAGT-5' & & NM_214131 \\
\hline
\end{tabular}

cDNA was amplified in a $20 \mu \mathrm{l}$ PCR reaction, which contained $1 \mathrm{U}$ Taq polymerase (Intron Biotechnology, Inc., Seongnam, Korea), 2 mM deoxyribonucleoside triphosphate (dNTP) mix and $10 \mathrm{pM}$ of each gene-specific primer. Quantitative PCR was performed with $1 \mu \mathrm{l}$ cDNA template added to $10 \mu \mathrm{l} 2 \mathrm{X}$ SYBR Premix Ex Taq (Takara Bio, Inc.) containing specific primers at a concentration of $10 \mathrm{pM}$ each. The reactions were carried out for 40 cycles and the cycling parameters were as follows: denaturation at $95^{\circ} \mathrm{C}$ for $30 \mathrm{sec}$, annealing at $55^{\circ} \mathrm{C}$ for $30 \mathrm{sec}$ and extension at $72^{\circ} \mathrm{C}$ for $30 \mathrm{sec}$. All oligonucleotide primer sequences are presented in Table I. The fluorescence intensity was measured at the end of the extension phase of each cycle. The threshold value for the fluorescence intensity of all samples was set manually. The reaction cycle at which the PCR products exceeded this fluorescence intensity threshold was deemed the threshold cycle $(\mathrm{Ct})$ in the exponential phase of the PCR amplification. The expression of each target gene was quantified relative to that of the internal control gene (GAPDH). The relative quantification was based on a comparison of $\mathrm{Ct}$ values at a constant fluorescence intensity. The amount of transcript present was inversely related to the observed $\mathrm{Ct}$ and, for each 2-fold dilution in the amount of transcript, $\mathrm{Ct}$ was expected to increase by one. The relative expression $(\mathrm{R})$ was calculated using the following equation: $\mathrm{R}=2^{-[\Delta \mathrm{Ct} \text { sample }-\Delta \mathrm{Ct} \text { control }]}$. To determine a normalized arbitrary value for each gene, each obtained value was normalized to that of GAPDH. The experiments were repeated at least 4 times.

Experimental design. In experiment 1, the effects of various concentrations $(0,1$ and $3 \%$ ) of ethanol treatment during IVM on nuclear maturation were examined. In experiment 2, the effects of ethanol treatment during IVM on intracellular levels of GSH and ROS were investigated. In experiment 3, the effects of ethanol treatment during IVM on subsequent embryonic development of PA and IVF embryos were examined. In experiment 4 , the effects of ethanol treatment on the mRNA expression of PCNA, PARP-1, Bak, Bax and caspase-3 in the COCs were analyzed.
Statistical analysis. Statistical analyses were performed using SPSS 17.0 software (SPSS, Inc., Chicago, IL, USA). Percentage data (e.g., rates of maturation, cleavage, blastocyst formation and number of nuclei) were compared by one-way analysis of variance (ANOVA), followed by Duncan's multiple range test. All results are expressed as the means \pm SEM. A value of $\mathrm{P}<0.05$ was considered to indicate a statistically significant difference.

\section{Results}

Effects of ethanol on nuclear maturation during IVM. There was no significant difference in maturation (MII stage) between the control group $(70.3 \%)$ and the $1 \%$ ethanol group $(59.8 \%)$ (Table II). However, the $3 \%$ ethanol group $(34.0 \%)$ showed a significantly decreased $(\mathrm{P}<0.05)$ number of MII stage oocytes compared with the control group. In addition, the 3\% group had a significantly increased number of MI oocytes $(19.3$ vs. 11.0\%) $(\mathrm{P}<0.05)$, as well as AT-I oocytes (44.3 vs. $17.5 \%$ ) compared with the control group.

Effects of ethanol on intracellular GSH and ROS levels during IVM. Ethanol treatment decreased the intracellular GSH levels $(\mathrm{P}<0.05)$ and increased ROS generation $(\mathrm{P}<0.05)$ in MII oocytes derived from the maturation medium supplemented with 1 and 3\% ethanol (Fig. 1).

Effects of the addition of ethanol to IVM medium on subsequent embryonic development following PA and IVF. Mature oocytes from each IVM group were subjected to PA. The cleavage rate was significantly lower $(\mathrm{P}<0.05)$ in the $3 \%$ ethanol group (51.6\%) than the control group (86.9\%) and the $1 \%$ group $(78.8 \%$ ) (Table III). For the cleavage pattern, there were significantly fewer 4- to 5-cell PA embryos in the $3 \%$ ethanol group than in the other groups (Fig. 2A). However, no significant differences were observed in the cleavage pattern of 2- to 3-cell PA embryos and 6- to 8-cell PA embryos. The $3 \%$ ethanol group had the lowest blastocyst 
Table II. Effects of ethanol treatment during porcine IVM on nuclear maturation.

No. of oocytes at different stages of maturation

\begin{tabular}{lccccc}
$\begin{array}{l}\text { Ethanol } \\
\text { concentration } \\
(\%)\end{array}$ & $\begin{array}{c}\text { No. of oocytes } \\
\text { cultured for } \\
\text { maturation }^{\mathrm{a}}\end{array}$ & $\begin{array}{c}\text { Germinal } \\
\text { vesicle }(\%)\end{array}$ & Metaphase I $(\%)$ & $\begin{array}{c}\text { Anaphase- } \\
\text { telophase I }(\%)\end{array}$ & Metaphase II (\%) \\
\cline { 3 - 6 } $0($ control) & 172 & $2(1.2 \pm 1.2)$ & $19(11.0 \pm 0.4)^{\mathrm{b}}$ & $30(17.5 \pm 1.4)^{\mathrm{b}}$ & $121(70.3 \pm 1.5)^{\mathrm{b}}$ \\
1 & 167 & $2(1.2 \pm 0.6)$ & $20(12.0 \pm 1.7)^{\mathrm{b}}$ & $45(27.0 \pm 3.9)^{\mathrm{b}}$ & $100(59.8 \pm 5.6)^{\mathrm{b}}$ \\
3 & 170 & $4(2.3 \pm 1.5)$ & $33(19.3 \pm 2.3)^{\mathrm{c}}$ & $75(44.3 \pm 4.4)^{\mathrm{c}}$ & $58(34.0 \pm 2.2)^{\mathrm{c}}$ \\
\hline
\end{tabular}

${ }^{a}$ Experiments repeated 3 times; ${ }^{b, c}$ Values with different letters in superscript within a column indicate a statistically significant difference $(\mathrm{P}<0.05)$ IVM, in vitro maturation.

Table III. Effects of ethanol treatment during IVM on embryonic development in porcine PA embryos.

\begin{tabular}{lcccr}
\hline \multirow{2}{*}{$\begin{array}{l}\text { Ethanol } \\
\text { concentration }(\%)\end{array}$} & $\begin{array}{c}\text { No. of embryos } \\
\text { cultured }\end{array}$ & \multicolumn{2}{c}{ No. of embryos developed into (\%) } & \\
\cline { 3 - 4 } & 130 & $113(86.9 \pm 2.4)^{\mathrm{b}}$ & $67(51.5 \pm 2.7)^{\mathrm{b}}$ & $\begin{array}{c}\text { Total cell numbe } \\
\text { in blastocyst (N) }\end{array}$ \\
\hline 0 (control) & 118 & $93(78.8 \pm 2.4)^{\mathrm{b}}$ & $43(36.4 \pm 5.0)^{\mathrm{c}}$ & $65.0 \pm 5.1^{\mathrm{b}}(12)$ \\
1 & 97 & $50(51.6 \pm 3.9)^{\mathrm{c}}$ & $11(11.3 \pm 0.3)^{\mathrm{d}}$ & $52.3 \pm 3.8^{\mathrm{c}}(12)$ \\
3 & 97 & Blastocysts & $30.6 \pm 3.1^{\mathrm{d}}(11)$ \\
\hline
\end{tabular}

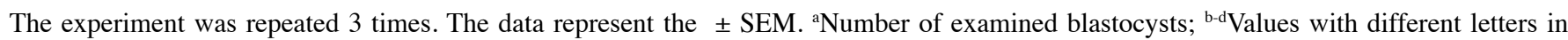
superscript within a column indicate a statistically significant difference $(\mathrm{P}<0.05)$. IVM, in vitro maturation; $\mathrm{PA}$, parthenogenetic activation.
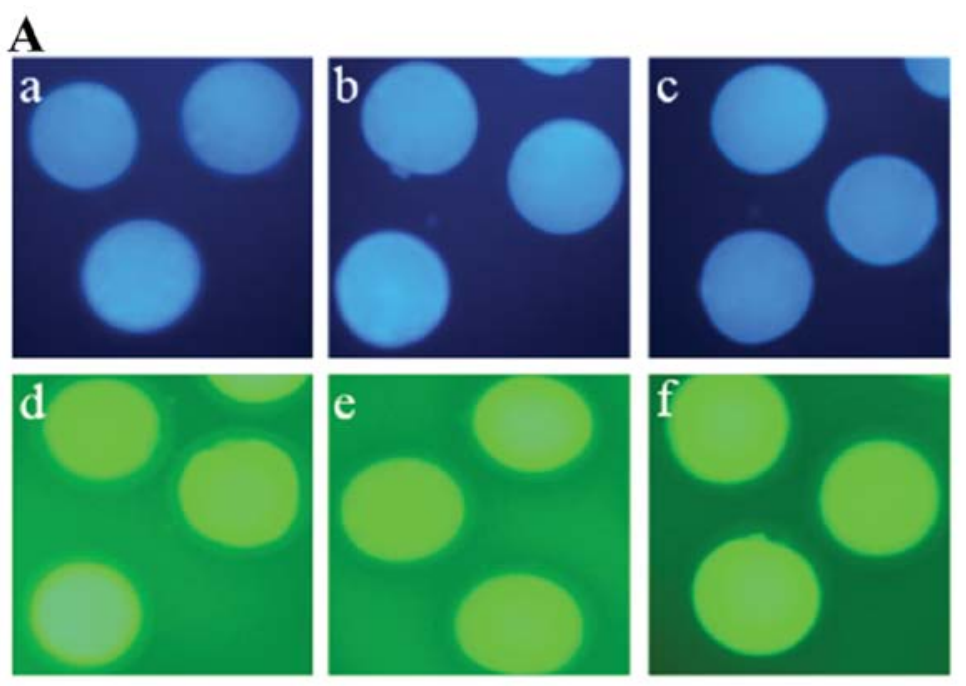

B

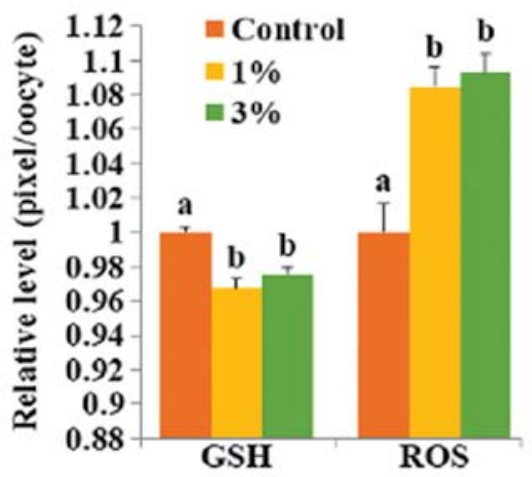

Figure 1. Epifluorescence photomicrographic images of in vitro matured porcine oocytes. (A) Oocytes were stained with (a-c) Cell Tracker Blue and (d-f) 2',7'-dichlorodihydrofluorescein diacetate ( $\left.\mathrm{H}_{2} \mathrm{DCFDA}\right)$ to detect intracellular levels of glutathione (GSH) and reactive oxygen species (ROS), respectively. Metaphase II (MII) oocytes derived from the maturation medium supplemented with (a and d) $1 \%$ ethanol, (b and e) $3 \%$ ethanol, and (c and f) without ethanol. (B) Relative levels of intracellular GSH and ROS in in vitro matured porcine oocytes between the 3 groups (1,3\% and without ethanol treatment). For each analysis (GSH and ROS levels), bars with different letters ( $\mathrm{a}$ and $\mathrm{b}$ ) indicate a statistically significant difference between groups $(\mathrm{P}<0.05)$. Total no. of examined oocytes: $\mathrm{GSH}$ samples, $\mathrm{n}=28$; $\mathrm{ROS}$ samples, $\mathrm{nN}=28$. The experiment was replicated 3 times.

formation rates $(\mathrm{P}<0.05)$ and total cell numbers $(11.3 \%$ and 30.6, respectively) compared with the other groups (Table III). The blastocyst formation rates and total cell number of the $1 \%$ ethanol group (36.4 and $52.3 \%$, respectively) were significantly lower $(\mathrm{P}<0.05)$ than those of the control group $(51.5$ and $65.0 \%$, respectively). The blastocyst formation rates and total cell number of blastocyts tended to decrease as the ethanol concentration increased (Table III). When comparing blastocyst formation patterns on day 7, early, expanded and hatched PA blastocyst numbers were significantly $(\mathrm{P}<0.05)$ lower in the 3\% ethanol group than in the other groups (Fig. 2B). However, there were no statistically significant differences in 
Table IV. Effects of ethanol treatment during IVM on embryonic development following IVF.

\begin{tabular}{lcccc}
\hline \multirow{2}{*}{$\begin{array}{l}\text { Ethanol } \\
\text { concentration (\%) }\end{array}$} & $\begin{array}{c}\text { No. of embryos } \\
\text { cultured }\end{array}$ & \multicolumn{2}{c}{ No. of embryos developed into (\%) } & $\begin{array}{c}\text { Total cell number in } \\
\text { blastocyst }(\mathrm{N})^{\mathrm{a}}\end{array}$ \\
\cline { 3 - 4 } 0 (control) & 201 & $142(70.6 \pm 0.7)^{\mathrm{b}}$ & $57(28.4 \pm 3.3)^{\mathrm{b}}$ & $64.8 \pm 4.5^{\mathrm{b}}(12)$ \\
1 & 183 & $121(65.6 \pm 1.3)^{\mathrm{c}}$ & $40(21.9 \pm 2.0)^{\mathrm{c}}$ & $50.2 \pm 2.5^{\mathrm{c}}(13)$ \\
3 & 137 & $73(53.3 \pm 1.5)^{\mathrm{d}}$ & $4(2.9 \pm 1.4)^{\mathrm{d}}$ & $27.3 \pm 4.7^{\mathrm{d}}(4)$ \\
\hline
\end{tabular}

The experiment was repeated 5 times. The data represent the means \pm SEM. ${ }^{\mathrm{a} N u m b e r}$ of examined blastocysts; ${ }^{\mathrm{b}-\mathrm{d}}$ Values with different letters in superscript within a column indicate a statistically significant difference $(\mathrm{P}<0.05)$. IVM, in vitro maturation; IVF, in vitro fertilization.
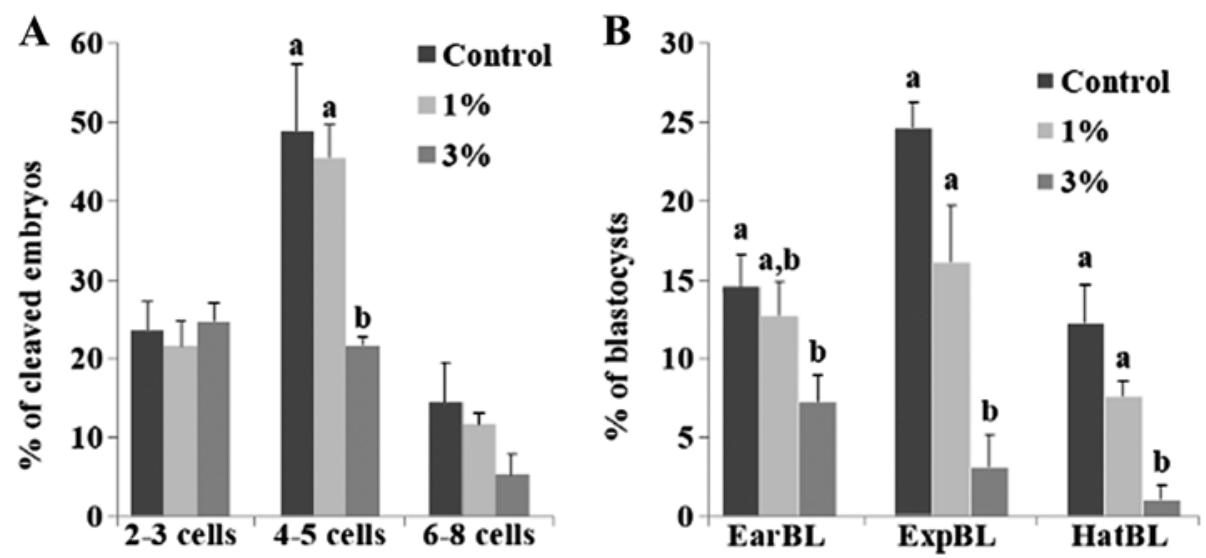

Figure 2. (A) Effects of various concentrations of ethanol during in vitro maturation (IVM) on the cleavage pattern of parthenogenetic activation (PA) embryos on day 2 and (B) the percentage of PA embryos that developed into blastocysts on day 7 . For each endpoint, bars with different letters (a and b) indicate a statistically significant difference between groups $(\mathrm{P}<0.05)$ for different concentrations of ethanol. EarBL, early blastocyst; ExpBL, expanded blastocyst; HatBL, hatched blastocyst. The experiment was repeated 3 times.
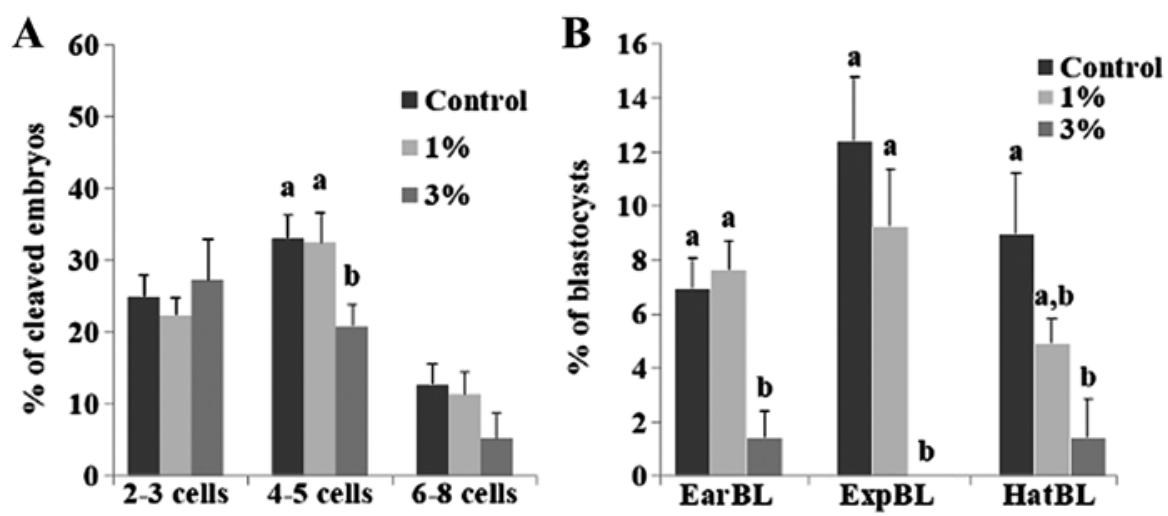

Figure 3. (A) Effects of various concentrations of ethanol during in vitro maturation (IVM) on the cleavage pattern of in vitro fertilization (IVF) embryos on day 2 and (B) the percentage of IVF embryos that developed into blastocysts on day 7. For each endpoint, bars with different letters (a and b) indicate a statistically significant difference $(\mathrm{P}<0.05)$ for different concentrations of ethanol. EarBL, early blastocyst; ExpBL, expanded blastocyst; HatBL, hatched blastocyst. The experiment was repeated 5 times.

the blastocyst formation patterns between the control and the $1 \%$ ethanol groups.

As shown in Table IV, in vitro fertilized embryos from the $3 \%$ ethanol group displayed the lowest cleavage rates $(\mathrm{P}<0.05)$, blastocyst formation rates and total cell numbers (53.3, 2.9 and $27.3 \%$, respectively) as compared with the other groups. The cleavage rates, blastocyst formation rates and total cell numbers were significantly lower $(\mathrm{P}<0.05)$ in the $1 \%$ ethanol group $(65.6$,
21.9 and $50.2 \%$, respectively) than the control group (70.6, $28 . \%$ and $64.8 \%$, respectively). On day 2 , there were significantly fewer 4 - to 5-cell IVF embryos in the $3 \%$ ethanol group compared with the other groups, and no significant difference was observed in the cleavage patterns of 2- to 3-cell IVF embryos and 6- to 8-cell IVF embryos (Fig. 3A). The early, expanded and hatched IVF blastocyst formation rates on day 7 were significantly $(\mathrm{P}<0.05)$ lower in the $3 \%$ ethanol group 


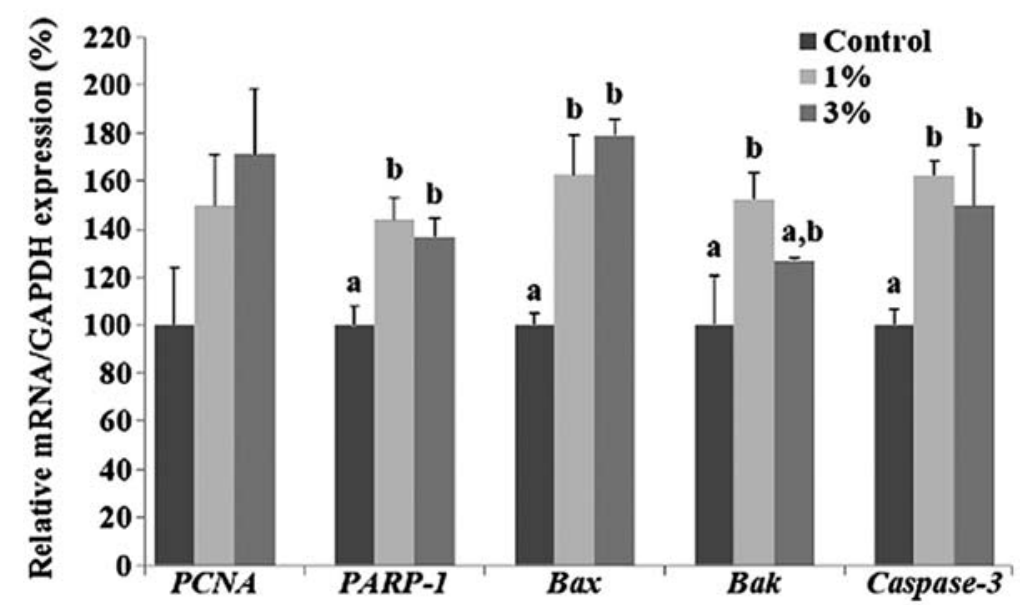

Figure 4. mRNA expression levels (mean \pm SEM) of proliferating cell nuclear (PCNA), poly(ADP-ribose) polymerase-1 (PARP-1), Bax, Bak, and caspase-3 in cumulus oocyte complexes (COCs) treated with ethanol during in vitro maturation (IVM). Within the same target mRNA, bars with different letters indicate a statistically significant difference between groups $(\mathrm{P}<0.05)$. The experiment was replicated 3 times.

than in the other groups (Fig. 3B). However, no statistically significant difference was observed between the control and $1 \%$ ethanol groups.

Effects of ethanol treatment during IVM on gene expression in the COCs. To examine the expression of DNA repair-related and apoptosis-related genes, we evaluated the mRNA expression levels of PCNA, PARP-1, Bax, Bak and caspase- 3 in the COCs of each group (Fig. 4). The COCs derived from the the $1 \%$ ethanol group showed significantly higher $(\mathrm{P}<0.05)$ mRNA expression levels of PARP-1, Bax, Bak and caspase-3 compared to those from the control group. The $3 \%$ ethanol group had significantly increased $(\mathrm{P}<0.05)$ PARP-1, Bax, Bak and caspase-3 mRNA expression levels in the COCs compared with the control group. No significant difference in PCNA transcript levels was observed in the 1 or $3 \%$ ethanol groups compared with the control group.

\section{Discussion}

Assisted reproduction technology (ART) strategies, including IVP of embryos, have been developed and used over several decades, and their application in porcine reproduction is well established worldwide (26). However, there are still many unresolved issues in current IVM-IVF systems, which are inefficient compared with in vivo systems.

The pig is a particularly difficult species in which to obtain high rates of fertilization and subsequent blastocyst development in vitro (27). The major obstacles that still need to be overcome are in vitro oocyte cytoplasmic maturation and the high incidence of polyspermy following IVF, as well as a low development rate and poor quality of blastocysts at the end of culture $(28,29)$. Therefore, the addition of various pharmacological compounds has been examined in an attempt to improve the quality of in vitro-produced porcine embryos. During these efforts, ethanol has been frequently used as a solvent for some compounds, such as lanosterol and MAS $(3,4)$. However, studies on the effects of ethanol treatment during IVM are limited. In the present study, we demonstrated that treatment with a low ethanol concentration during IVM had detrimental effects on oocyte maturation and the subsequent embryonic development of PA and IVF embryos.

Oocyte maturation includes both nuclear and cytoplasmic maturation. First, in terms of nuclear maturation, IVM medium with $3 \%$ ethanol significantly decreased the maturation rate. This finding therefore suggests that $3 \%$ ethanol-treated oocytes fail to progress beyond the AT-I stage. We also investigated intracellular GSH and ROS levels to examine cytoplasmic maturation. Intracellular levels of GSH and ROS are critical factors that influence oocyte IVM and oocyte developmental potential following PA and IVF $(19,30,31)$. Intracellular GSH is a molecular marker in mature oocytes that predicts cytoplasmic maturation in porcine oocytes (32), and low intracellular GSH concentrations are responsible for lower developmental competence in porcine oocytes (33). Moreover, intracellular GSH plays a pivotal role protecting cells against the destructive effects of reactive oxygen intermediates and free radicals (34). In our study, ethanol treatment (1 and 3\%) during IVM significantly increased intracellular ROS levels and decreased intracellular GSH levels. We demonstrated that ethanol treatment at levels $>1 \%$ had detrimental effects on the cytoplasmic maturation of porcine oocytes.

Embryonic development and blastocyst viability following PA and IVF also decreased by 1 and 3\% ethanol treatment due to the detrimental effects of ethanol on cytoplasmic maturation. A previous study that examined the effects of ethanol on bovine embryonic development demonstrated that the cleavage rate was not significantly affected by $1 \%$ ethanol, but that the blastocyst formation rate of IVF was significantly decreased by $1 \%$ ethanol (35). In comparison with bovine, our results indicated that $1 \%$ ethanol significantly decreased porcine blastocyst formation rates and also decreased the cleavage rate of IVF porcine embryos. This difference may be due to the different species used or to the fact that porcine $\mathrm{COCs}$ are more sensitive to ethanol.

Modifications in culture environment modulate gene expression in mammalian cells and embryos $(36,37)$. For example, mouse blastocyst formation depends on oocyte transcripts 
generated before fertilization (38). The presence of surrounding cumulus cells is responsible for appropriate oocyte maturation and the developmental competence of oocytes. Cumulus cells participate in oocyte development during IVM by secreting soluble factors, which induce developmental competence (39). Moreover, apoptosis plays a critical role in development and differentiation. Environmental stressors, such as those created by in vitro culture, can cause unplanned apoptosis in cultured embryos, which may lead to embryonic arrest or abnormal development and lower embryo viability $(40,41)$. Therefore, we examined the mRNA expression levels of DNA repair-related and apoptosis-related genes in the COCs. PCNA is a necessary component of DNA repair machinery, and a PCNA signal suggests the activation of the DNA repair process $(42,43)$. In this study, no significant differences in PCNA transcript levels were observed in the 1 or $3 \%$ ethanol groups compared with the control group. However, considering that the PCNA transcript tended to increase as ethanol concentration increased, this result appears to be due to DNA damage induced by ethanol. PARP-1 is emerging as an important activator of caspase-independent cell death (18). Among multiple apoptotic pathways activated in neurons by ethanol, PARP-1 pathways also play a role in the subsequent apoptotic death (14). In the present study, the 1 and 3\% ethanol groups had significantly increased PARP-1 transcript levels in the COCs compared to the control group. These results indicate that the PARP-1-related apoptotic pathway may be induced by ethanol treatment during IVM in the COCs. The expression of PARP-1 may be useful as another indicator of apoptosis in porcine oocytes. Bax, Bak, and caspase- 3 are also associated with apoptosis initiated by the mitochondrial release of apoptogenic factors (44). In this study, the $1 \%$ ethanol group had increased Bax, Bak and caspase-3 transcript levels in the COCs, and the 3\% ethanol group had increased Bax and caspase-3 transcript levels in the COCs, thereby suggesting that ethanol promoted the expression of pro-apoptotic genes in the intrinsic apoptotic pathway in oocytes and cumulus cells. Fine modulation of gene expression plays a key role in the proper alterations and transitions that occur during oocyte maturation and development. These processes seem to be largely under the control of post-transcriptional regulatory mechanisms and mostly driven by cytoplasmic components (45). In this regard, changes in gene expression levels are likely related to the observed decrease in the blastocyst formation rate and blastocyst quality (less expanded and hatched blastocysts in the 1 and 3\% ethanol-treated groups), which may have also affected the number of nuclei in the blastocysts. The decreased cell number in blastocysts derived from ethanol-treated mature oocytes may be due to promoted apoptosis. These results suggest that ethanol supplementation to the maturation medium significantly affects the expression of apoptosis-related genes in mature oocytes and cumulus cells, thereby leading to an overall increase in their susceptibility to apoptosis.

The molecular mechanisms through which ethanol exerts its pro-apoptotic effects on oocyte maturation and subsequent embryonic development are unclear. In previous studies that examined ethanol-induced oxidative stress on fetal cortical neurons, it was shown that multiple apoptotic pathways were activated in neurons by ethanol, including the well-documented intrinsic components associated with caspase (caspase-3) activation and DNA damage $(46,47)$. In cultured fetal cortical rat neurons, ethanol elicits an increase in ROS and, subsequently, a decrease in cellular GSH (46). DNA damage caused by ROS then activates PARP-1-related DNA repair processes. However, with longer term ethanol exposure, the hyperactivation of PARP-1 occurs, which may cause pro-apoptotic activities (14). Yu et al $(48,49)$ demonstrated that PARP-1 activation signals cause the translocation of apoptosis-inducing factor (AIF), a $67 \mathrm{kDa}$ flavoprotein, from the mitochondria to the nucleus, resulting in a caspase-independent pathway of programmed cell death. In turn, the upregulation of PARP-1 expression and poly(ADP-ribose) (PAR) formation cause apoptotic cell death $(14,50)$.

In this study, we demonstrated that ethanol promoted the expression of both pro-apoptotic genes in the intrinsic apoptotic pathway and PARP-1 in oocytes and cumulus cells. It is therefore suggested, that ethanol increases intracellular ROS levels, which is strongly related to apoptosis, thus resulting in two possible mechanisms performed by its cascade of caspase-dependent apoptotic events and PARP-1-related apoptotic pathways (caspase-independent).

In conclusion, ethanol treatment during IVM was detrimental for the cytoplasmic maturation of porcine oocytes by increasing intracellular ROS levels, thereby decreasing GSH concentrations and upregulating apoptosis-related genes. Furthermore, porcine oocytes treated with $>1 \%$ ethanol may have reduced developmental competence, which would greatly decrease blastocyst formation and the total cell number of blastocysts in PA- and IVF-derived embryos. Therefore, our results suggest that ethanol diminishes the quality of porcine oocytes and the subsequent in vitro development when IVM medium is supplemented with $>1 \%$ ethanol.

\section{Acknowledgements}

This study was supported, in part, by a grant from the National Research Foundation of Korea Grant Government (NRF2012R1A1A4A01004885, NRF-2013R1A2A2A04008751), Republic of Korea.

\section{References}

1. Prather RS, Hawley RJ, Carter DB, Lai L and Greenstein JL: Transgenic swine for biomedicine and agriculture. Theriogenology 59: 115-123, 2003.

2. Meurens F, Summerfield A, Nauwynck H, Saif L and Gerdts V: The pig: a model for human infectious diseases. Trends Microbiol 20: 50-57, 2012.

3. Marco-Jiménez F, Llobat L and Vicente JS: Effects of lanosterol on in vitro maturation of porcine oocytes. Anim Reprod Sci 117: 288-294, 2010.

4. Avery B, Faerge I, Grøndahl C and Ottesen J: Nuclear maturation and embryo development of bovine oocytes, matured in a semi-defined medium supplemented with meiosis activating sterol (MAS). Theriogenology 51: 367, 1999.

5. Martino A, Songsasen N and Leibo SP: Development into blastocysts of bovine oocytes cryopreserved by ultra-rapid cooling. Biol Reprod 54: 1059-1069, 1996.

6. Vajta G, Holm P, Kuwayama M, et al: Open Pulled Straw (OPS) vitrification: a new way to reduce cryoinjuries of bovine ova and embryos. Mol Reprod Dev 51: 53-58, 1998.

7. Barboni B and Mattioli M: Oocyte maturation involves important changes required for activation competence. Reprod Domest Anim 31: 589-594, 1996.

8. Fukui Y, Sawai K, Furudate M, Sato N, Iwazumi Y and Ohsaki K: Parthenogenetic development of bovine oocytes treated with ethanol and cytochalasin B after in vitro maturation. Mol Reprod Dev 33: 357-362, 1992. 
9. Balakier H and Casper RF: Experimentally induced parthenogenetic activation of human oocytes. Hum Reprod 8: 740-743, 1993

10. Rybouchkin A, Dozortsev D, De Sutter P and Dhont M: Factors affecting the role of the spindle during early response of mouse oocytes to ethanol stimulation. J Exp Zool 275: 469-475, 1996.

11. Novitskiy G, Traore K, Wang L, Trush MA and Mezey E: Effects of ethanol and acetaldehyde on reactive oxygen species production in rat hepatic stellate cells. Alcohol Clin Exp Res 30: $1429-1435,2006$.

12. Mameli M, Botta P, Zamudio PA, Zucca S and Valenzuela CF Ethanol decreases Purkinje neuron excitability by increasing GABA release in rat cerebellar slices. J Pharmacol Exp Ther 327: 910-917, 2008.

13. Caires KC, Shima CM, de Avila J and McLean DJ: Acute ethanol exposure affects spermatogonial stem cell homeostasis in pre-pubertal mice. Reprod Toxicol 33: 76-84, 2012.

14. Cherian PP, Schenker S and Henderson GI: Ethanol-mediated DNA damage and PARP-1 apoptotic responses in cultured fetal cortical neurons. Alcohol Clin Exp Res 32: 1884-1892, 2008

15. Hengartner MO: The biochemistry of apoptosis. Nature 407: 770-776, 2000

16. Kameshita I, Matsuda Z, Taniguchi $\mathrm{T}$ and Shizuta $\mathrm{Y}$ : Poly (ADP-Ribose) synthetase. Separation and identification of three proteolytic fragments as the substrate-binding domain, the DNA-binding domain, and the automodification domain. J Bioll Chem 259: 4770-4776, 1984.

17. Virág L and Szabó C: The therapeutic potential of poly (ADP-ribose) polymerase inhibitors. Pharmacol Rev 54: 375-429, 2002.

18. Hong SJ, Dawson TM and Dawson VL: Nuclear and mitochondrial conversations in cell death: PARP-1 and AIF signaling. Trends Pharmacol Sci 25: 259-264, 2004.

19. You J, Kim J, Lim J and Lee E: Anthocyanin stimulates in vitro development of cloned pig embryos by increasing the intracellular glutathione level and inhibiting reactive oxygen species. Theriogenology 74: 777-785, 2010

20. Nasr-Esfahani MH, Aitken JR and Johnson MH: Hydrogen peroxide levels in mouse oocytes and early cleavage stage embryos developed in vitro or in vivo. Development 109 : 501-507, 1990

21. Baker MA, Cerniglia GJ and Zaman A: Microtiter plate assay for the measurement of glutathione and glutathione disulfide in large numbers of biological samples. Anal Biochem 190: $360-365,1990$

22. Abeydeera LR and Day BN: In vitro penetration of pig oocytes in a modified Tris-buffered medium: effect of BSA, caffeine and calcium. Theriogenology 48: 537-544, 1997.

23. Gil MA, Ruiz M, Vazquez JM, Roca J, Day BN and Martinez EA: Effect of short periods of sperm-oocyte coincubation during in vitro fertilization on embryo development in pigs. Theriogenology 62: 544-552, 2004.

24. Yoshioka K, Suzuki C, Tanaka A, Anas IM and Iwamura S: Birth of piglets derived from porcine zygotes cultured in a chemically defined medium. Biol Reprod 66: 112-119, 2002.

25. Cheng TC, Huang CC, Huang LS, Chen CI, Lee MS and Liu JY: Evaluation of mouse blastocyst implantation rate by morphology grading. Chin J Physiol 47: 43-47, 2004.

26. Hall V, Hinrichs K, Lazzari G, Betts DH and Hyttel P: Early embryonic development, assisted reproductive technologies, and pluripotent stem cell biology in domestic mammals. Vet J 197: $128-142,2013$

27. Gil MA, Cuello C, Parrilla I, Vazquez JM, Roca J and Martinez EA: Advances in swine in vitro embryo production technologies. Reprod Domest Anim 45 (Suppl 2): S40-S48, 2010

28. Funahashi $\mathrm{H}$ and Day BN: Advances in in vitro production of pig embryos. J Reprod Fertil Suppl 52: 271-283, 1997

29. Coy P and Romar R: In vitro production of pig embryos: a point of view. Reprod Fertil Dev 14: 275-286, 2002.

30. De Matos DG and Furnus CC: The importance of having high glutathione (GSH) level after bovine in vitro maturation on embryo development: effect of beta-mercaptoethanol, cysteine and cystine. Theriogenology 53: 761-771, 2000.
31. Abeydeera LR, Wang WH, Cantley TC, Prather RS and Day BN: Presence of beta-mercaptoethanol can increase the glutathione content of pig oocytes matured in vitro and the rate of blastocyst development after in vitro fertilization. Theriogenology 50 747-756, 1998.

32. Luberda Z: The role of glutathione in mammalian gametes. Reprod Biol 5: 5-17, 2005

33. Brad AM, Bormann CL, Swain JE, et al: Glutathione and adenosine triphosphate content of in vivo and in vitro matured porcine oocytes. Mol Reprod Dev 64: 492-498, 2003.

34. Meister A: Selective modification of glutathione metabolism. Science 220: 472-477, 1983.

35. Avery B and Greve T: Effects of ethanol and dimethylsulphoxide on nuclear and cytoplasmic maturation of bovine cumulus-oocyte complexes. Mol Reprod Dev 55: 438-445, 2000.

36. Park SH, Park SB and Kim NH: Expression of early development-related genes in bovine nuclear transferred and fertilized embryos. Zygote 11: 355-360, 2003.

37. Zhou W, Xiang T, Walker S, et al: Global gene expression analysis of bovine blastocysts produced by multiple methods. Mol Reprod Dev 75: 744-758, 2008.

38. De Sousa PA,Caveney A, Westhusin ME and Watson AJ: Temporal patterns of embryonic gene expression and their dependence on oogenetic factors. Theriogenology 49: 115-128, 1998.

39. Hashimoto S, Saeki K, Nagao Y, Minami N, Yamada M and Utsumi K: Effects of cumulus cell density during in vitro maturation on the developmental competence of bovine oocytes. Theriogenology 49: 1451-1463, 1998 .

40. Jurisicova A, Latham KE, Casper RF and Varmuza SL: Expression and regulation of genes associated with cell death during murine preimplantation embryo development. Mol Reprod Dev 51: 243-253, 1998.

41. Byrne AT, Southgate J, Brison DR and Leese HJ: Analysis of apoptosis in the preimplantation bovine embryo using TUNEL. J Reprod Fertil 117: 97-105, 1999.

42. Makarevich AV and Markkula M: Apoptosis and cell proliferation potential of bovine embryos stimulated with insulin-like growth factor I during in vitro maturation and culture. Biol Reprod 66: 386-392, 2002.

43. Wu MH, Chang JH and Yung BY: Resistance to UV-induced cell-killing in nucleophosmin/B23 over-expressed NIH 3T3 fibroblasts: enhancement of DNA repair and up-regulation of PCNA in association with nucleophosmin/B23 over-expression. Carcinogenesis 23: 93-100, 2002.

44. Zong WX, Li C, Hatzivassiliou G, et al: Bax and Bak can localize to the endoplasmic reticulum to initiate apoptosis. J Cell Biol 162: 59-69, 2003.

45. Gandolfi TA and Gandolfi F: The maternal legacy to the embryo: cytoplasmic components and their effects on early development. Theriogenology 55: 1255-1276, 2001.

46. Ramachandran V, Watts LT, Maffi SK, Chen J, Schenker S and Henderson G: Ethanol-induced oxidative stress precedes mitochondrially mediated apoptotic death of cultured fetal cortical neurons. J Neurosci Res 74: 577-588, 2003.

47. Ramachandran V, Perez A, Chen J, Senthil D, Schenker S and Henderson GI: In utero ethanol exposure causes mitochondrial dysfunction, which can result in apoptotic cell death in fetal brain: a potential role for 4-hydroxynonenal. Alcohol Clin Exp Res 25: 862-871, 2001

48. Yu SW, Wang H,Poitras MF, et al: Mediation of poly(ADP-ribose) polymerase-1-dependent cell death by apoptosis-inducing factor. Science 297: 259-263, 2002.

49. Yu SW, Andrabi SA, Wang H, et al: Apoptosis-inducing factor mediates poly(ADP-ribose) (PAR) polymer-induced cell death Proc Natl Acad Sci USA 103: 18314-18319, 2006.

50. Strosznajder JB, Czapski GA, Adamczyk A and Strosznajder RP: Poly(ADP-ribose) polymerase-1 in amyloid beta toxicity and Alzheimer's disease. Mol Neurobiol 46: 78-84, 2012. 